\title{
FTO Gene Polymorphisms Contribute to the Predisposition and Radiotherapy Efficiency of Nasopharyngeal Carcinoma
}

\section{Feng Xiao \\ Jianrong Zhou}

School of Nursing, Chongqing Medical University, Chongqing, 400016, People's Republic of China
Correspondence: Jianrong Zhou

School of Nursing, Chongqing Medical University, No. I Changda Road,

Jiulongpo District, Chongqing, 4000I6,

People's Republic of China

Email jianrong_zhou@2I cn.com
Background: Nasopharyngeal carcinoma (NP/ is mainly co ep red in East and Southeast Asia. This study aims to elucidate th potent associations of functional SNPs in the fat mass and obesity associated gene $\mathrm{TO}) \mathrm{NPC \text {risk }} \mathrm{d}$ radiotherapy outcomes in a Chinese population.

Methods: Functional SNP rs147 96 A, rs99396 T>A, rs7206790 C $>\mathrm{G}$, and rs8047395 A $>\mathrm{G}$ were genotyped and evaluat for their associations with NPC risk and radiotherapy outcomes.

Results: Both rs993960 (allele A rrsus allele $\mathrm{T}$ : $\mathrm{OR}=1.59 ; 95 \% \mathrm{CI}=1.17-2.17$; $P$-value $=0.003$ ) and rs804 95 (allele $C$ versus allele A: $\mathrm{OR}=0.76 ; 95 \% \mathrm{CI}=0.64-0.9$; $P$-value $=0.002$ ) yere signifio $\mathrm{ly}$ asso red with risk of NPC. GTEx showed risk allele A of rs9939609 an 17395 wor significantly associated with higher FTO mRNA levels in skeletal muscle ssue 1 so corroborated our findings. Meanwhile, both rs 1477196 (allele arsus al $G: \mathrm{OR}=1.64 ; 95 \% \mathrm{CI}=1.09-2.49 ; P$-value $=0.019$ ) and $\mathrm{rs} 9939609$ (all A ve is allel T: $\mathrm{OR}=0.61 ; 95 \% \mathrm{CI}=0.43-0.87 ; P$-value $=0.006$ ) were significantly ociated theompla remission (CR) of NPC.

Co. " on: Our study identified that FTO polymorphisms contributed to the susceptibility and rac herapy efficacy of NPC. These results shed light on the potential of establishing markers fo redicting risk and personalized treatment of NPC.

ywords: nasopharyngeal carcinoma, FTO, predisposition, radiotherapy

\section{Introduction}

Nasopharyngeal Carcinoma (NPC), a relatively rare malignant epithelial carcinoma arising from the nasopharyngeal mucosal lining, is mainly concentrated in East and Southeast Asia, the Arctic, North Africa, and the Middle East. ${ }^{1-3}$ According to the Cancer Statistics in China, 2015, which was reported by the national office for cancer prevention and control of China, there were an estimated 60.6 thousand new NPC cases and 34.1 thousand NPC deaths annually. ${ }^{4}$ Well established risk factors for NPC include Epstein-Barr virus (EBV) infection, consumption of salt-cured fish, family history of NPC, consumption of other cured foods, smoking, etc. ${ }^{5}$ However, the specific mechanisms affecting the development of NPC and the effectiveness of treatment remain unclear. Thus, searching for markers of NPC predisposition and radiotherapy efficiency is of great clinical importance.

Single nucleotide polymorphisms (SNPs) have become important predictors of tumors and indicators of the effectiveness of response to radiation therapy. ${ }^{6-8}$ SNPs 
may affect gene expression, mRNA stability, and protein function. ${ }^{9}$ Among them, SNPs of the fat mass and obesity associated gene (FTO), the first obesity-related gene identified by genome-wide association studies (GWAS), has been linked to the occurrence, progression, and prognosis of many cancers, including breast cancer, ovarian cancer, Wilms tumor, thyroid cancer, pancreatic cancer, prostate cancer, colorectal cancer, etc. $^{10-19}$ This is because obesity plays a crucial role in the development and prognosis of cancers. ${ }^{20}$ Further, obesity also served as an emerging driver of head and neck cancers, ${ }^{21}$ especially central adiposity. ${ }^{22}$ The FTO gene, which was located at 16q12.2, is a nuclear protein of the AlkB related non-haem iron and 2-oxoglutarate-dependent oxygenase superfamily. ${ }^{10}$ It can mediate cytoplasmic m(6)Am demethylation in cancers. ${ }^{23,24}$ FTO polymorphisms are significantly associated with various human diseases, especially cancers. $^{16,25}$ Among them, rs1477196, rs9939609, rs7206790, and rs8047395 are mostly explored. ${ }^{16,26-30}$

Whether FTO gene polymorphisms contribute to the predisposition, even radiotherapy efficiency of NPC was still unexplored. In the current study, we first performed a systematic genetic analysis to further elucidate the associations of the potential functional SNPs (rs1477196 G>A, rs9939609 $\mathrm{T}>\mathrm{A}$, rs7206790 $\mathrm{C}>\mathrm{G}$, and rs8047395 $\mathrm{A}>\mathrm{G}$ ) the FTO gene with NPC risk and radiotherapy outcomes it a Chinese population. This study will provide clues to elucidate the pathogenesis of NPC nd to ther implement individualized radiotherapy patients.

\section{Patients and Metbods}

\section{Study Subjects}

In total $367 \mathrm{NPC}$ healthy controls br-age a gender ore included in this study. All the atient unden nt asopharyngoscopy and were histo rically Intified as NPC, while controls with any other kin umors or a personal family history of NPC were excluo The demographics and clinical characteristics of patiens were collected through medical record or inquiries. Five milliliters of peripheral blood was collected. All patients received radical external irradiation with or without cisplatin-based chemotherapy or both. Efficacy was evaluated by magnetic resonance imaging (MRI) directly after the end of radiotherapy, in accordance with the efficacy evaluation criteria for solid tumors (RECIST), defining the efficacy endpoint as complete remission (CR). EBV-VCA-IgA was tested using the
ELISA kit. All procedures performed in research involving human participants were in accordance with the Declaration of Helsinki. This study was approved by the Institute committees of the School of Nursing of Chongqing medical university, and informed consent was obtained from all subjects recruited for this study.

\section{DNA Extraction and Genotyping}

Genomic DNA was extracted with the peripheral blood DNA Extraction Kit (QIAamp DNA blood Mini Kit; Qiagen, Inc., Valencia, CA). Gen of the four SNPs (rs1477196, rs9939609, rs7 6790, and 8047395) was conducted using the Sequeno iPLEX Ma ARRAY system (Sequenom, Inc., S Diego, USA For quality control, a random selecte grou $10 \%$ of the samples was tested th $b$ different individuals with $100 \%$ concordar of res ts. All aboratory personnel were blind to 10 henotype si of the samples.

\section{Stati creal Analysi}

Sta tical analys was performed using SPSS 22.0 (IBM, Chi go, IL, US 4 , and a two-sided $P$-value of $<0.05$ was consio stat cally significant. Clinical characteristics NPC cases and healthy controls were compared by the $C$-squ test or Student's $t$-test. The Hardy-Weinberg equilibrium (HWE) was tested by Chi-squared test to test or deviation between observed and expected frequencies among controls. Odds ratios (ORs) and 95\% confidence intervals (CIs) were calculated by logistic regression model to estimate the association between the selected functional SNPs and NPC risk and radiotherapy efficiency, adjusted for the clinical characteristics.

\section{Results \\ Clinical Characteristics of NPC Cases and Controls}

As shown in Table 1, frequency distributions of age, gender, and drinking status were comparable in general between 367 NPC cases and 380 healthy controls $(P>0.05)$, which indicated the adequate frequency-matching strategy. However, we found the smoking status and EBV-VCA-IgA status were significantly different between the cases and controls $(P<0.001)$. Among the 367 NPC cases, $73 \%$ also received chemotherapy, which means $27 \%$ only received radiotherapy. For TNM stage, $34.9 \%$ were classified as I-II, while $65.1 \%$ were classified as III-IV. Of them, the radiotherapy efficacy of 254 (69.2\%) patients reached CR. 
Table I Clinical Characteristics of NPC Cases and Controls

\begin{tabular}{|c|c|c|c|}
\hline Variables & Cases $(n=367)$ & Controls $(n=380)$ & $P$-value \\
\hline Age & $49.7 \pm 10.9$ & $50.1 \pm 11.8$ & 0.631 \\
\hline \multicolumn{4}{|l|}{ Gender } \\
\hline Male & 257 (70.0\%) & 259 (68.2\%) & 0.581 \\
\hline Female & 110 (30.0\%) & $|2|(3 \mid .8 \%)$ & \\
\hline \multicolumn{4}{|l|}{ Smoking status } \\
\hline Ever-smokers & 154 (42.0\%) & $125(32.9 \%)$ & $<0.001$ \\
\hline Non-smokers & $213(58.0 \%)$ & 255 (67.1\%) & \\
\hline \multicolumn{4}{|l|}{ Drinking status } \\
\hline Drinkers & 143 (39.0\%) & I4I (37.1\%) & 601 \\
\hline Non-drinkers & 224 (6I.0\%) & 239 (62.9\%) & \\
\hline \multicolumn{4}{|l|}{$E B V-V C A-\lg A$} \\
\hline Positive & $24 I(65.7 \%)$ & $32(8.4 \%)$ & .001 \\
\hline Negative & $126(34.3 \%)$ & $348(91.6 \%)$ & \\
\hline \multicolumn{4}{|l|}{ Chemotherapy } \\
\hline Yes & $268(73.0 \%)$ & & \\
\hline No & 99 (27.0\%) & & \\
\hline \multicolumn{4}{|l|}{ TNM stage } \\
\hline I-II & 128 (34.9\%) & & \\
\hline III-IV & $239(65.1 \%)$ & & \\
\hline \multicolumn{4}{|c|}{ Complete remission } \\
\hline Yes & 254 (69.2\%) & & \\
\hline No & $113(30.8 \%)$ & & \\
\hline
\end{tabular}

\section{Chinese Population}

First, all four SNPs, including 1 177196, rs9939609, rs 7206790, and rs8047 5 , were in HWb yong the controls $(P>0.05)$, which in cated th appropriate representativeness of the control pop a As $\mathrm{s}^{\mathrm{y}}$ wn in Table 2, both rs9939609 allo A sus rele $\mathrm{T}: \mathrm{OR}=1.59 ; 95 \%$ $\mathrm{CI}=1.1 \quad 2.17 ; \quad$ value $=0,03$ ) and rs8047395 (allele $\mathrm{G}$ vers $\mathrm{Ol}$ - $\mathrm{OR}=0.76 ; \quad 95 \% \quad \mathrm{CI}=0.64-0.9$; $P$-value $=0.0$ were significantly associated with risk of NPC. The resul of the dominant model, recessive model, and co-additive model were all statistically significant for rs9939609 and rs8047395 (Bonferroni corrected $P$-values were still significant). Further, we summarized the risk alleles of the four SNPs together (Table 2, numbers of risk alleles ranged from 0-6). Compared with the subject with $\leq 3$ risk alleles, those with $>3$ risk alleles have a non-significantly increased risk of NPC $(\mathrm{OR}=1.27 ; 95 \% \quad \mathrm{CI}=0.91-1.78$; $P$-value $=0.154)$.
We further analyzed the eQTL effect of rs9939609 and rs8047395 using data from GTEx to assess whether they could affect the FTO mRNA expression. As shown in Figure 1, both the risk allele A of rs9939609 and rs8047395 were significantly associated with higher FTO mRNA levels in skeletal muscle tissue ( $P$-value: $4.2 \times 10^{-6} ; 2.2 \times 10^{-7}$, respectively).

\section{Association between Genetic Variations of the FTO Gene and the Efficacy of Radiotherapy in NPC Patients}

We also determined the associations between genetic variations of the FTO gene and the efficacy of radiotherapy in NPC patients (Table 3). Of the four SNPs, both rs 1477196 (allele A versus allele $\mathrm{G}$ : $\mathrm{OR}=1.64 ; 95 \% \mathrm{CI}=1.09-2.49$; $P$-value $=0.019$ ) and rs9939609 (allele A versus allele T: $\mathrm{OR}=0.61 ; 95 \% \mathrm{CI}=0.43-0.87 ; P$-value $=0.006)$ were significantly associated with CR of NPC. Results of the 
Table 2 Associations between Genetic Variations of the FTO Gene and Risk of NPC

\begin{tabular}{|c|c|c|c|c|}
\hline & Cases & Controls & OR $(95 \% \mathrm{Cl}) *$ & $P$-value \\
\hline \multicolumn{5}{|l|}{ rs 1477|96 } \\
\hline GG & 215 & 207 & I.00 (Reference) & \\
\hline AG & $|3|$ & 140 & $0.94(0.78-1.12)$ & 0.482 \\
\hline AA & 21 & 33 & $0.64(0.38-1.06)$ & 0.080 \\
\hline A vs $G$ & & & $0.86(0.72-1.03)$ & 0.100 \\
\hline Dominant & & & $0.88(0.7 \mid-1.09)$ & 0.235 \\
\hline Recessive & & & $0.66(0.4 I-1.08)$ & 0.101 \\
\hline \multicolumn{5}{|l|}{ rs9939609 } \\
\hline TT & 256 & 297 & I.00 (Reference) & \\
\hline AG & 102 & 80 & $1.54(1.08-2.19)$ & \\
\hline AA & 9 & 3 & $3.62(1.07-12.25)$ & 0.0 \\
\hline A vs $T$ & & & $1.59(1.17-2.17)$ & 0.00 \\
\hline Dominant & & & & 0.0 \\
\hline Recessive & & & $3.29(0.96, .24)$ & .058 \\
\hline \multicolumn{5}{|l|}{ rs7206790 } \\
\hline $\mathrm{CC}$ & 249 & 275 & & \\
\hline CG & 107 & 98 & & 0.234 \\
\hline GG & 11 & 7 & $-4.77)$ & 0.234 \\
\hline G vs $C$ & & & 1.28 & 0.118 \\
\hline Dominant & & & $1.29(0.91-1.04)$ & 0.157 \\
\hline Recessive & & & $(0.64-4.55)$ & 0.280 \\
\hline \multicolumn{5}{|l|}{ rs8047395 } \\
\hline $\mathrm{AA}$ & 163 & & .00 (Reference) & \\
\hline AG & 157 & & $0.65(0.49-0.85)$ & 0.002 \\
\hline GG & 47 & & $0.6 I(0.42-0.91)$ & 0.015 \\
\hline$G$ vs $A$ & & & $0.76(0.64-0.90)$ & 0.002 \\
\hline Dominant & & & $0.64(0.49-0.83)$ & 0.001 \\
\hline Recessive & & & $0.80(0.57-I . I I)$ & 0.186 \\
\hline \multicolumn{5}{|l|}{ Risk alleles } \\
\hline$\leq 3$ & & 238 & I.00 (Reference) & \\
\hline$>3$ & & 142 & $1.27(0.91-1.78)$ & 0.154 \\
\hline
\end{tabular}

Note: *Adjusted for age, gender, sm status, drinking s

and EBV-VCA-lgA status.

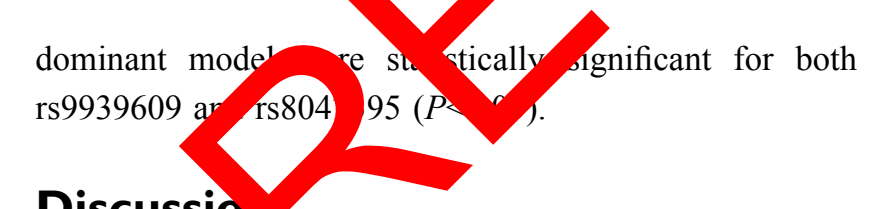

Discussio.

NPC causes great ${ }_{\mathbf{p}} \eta$ and inconvenience to the victims. It is of great significance to explore the mechanisms related to disease prevention and carry out individualized treatment. In the current study, we explored the associations between potential functional SNPs in the FTO gene associated with NPC risk and radiotherapy outcomes in a Chinese population. We revealed that both rs9939609 and rs8047395 were significantly associated with risk of NPC. Meanwhile, rs1477196 and rs9939609 were significantly associated with CR of NPC. To the best of our knowledge, this is the first study to reveal the essential role of FTO polymorphisms in the susceptibility and radiotherapy efficacy.

Excess body adiposity, commonly expressed as body mass index (BMI), has been identified as a risk factor for many common adult cancers. ${ }^{31}$ FTO was both the first GWAS identified obesity-related gene and first identified N6-methyladenosine $\left(\mathrm{m}^{6} \mathrm{~A}\right)$ demethylase of eukaryotic mRNA. ${ }^{10,32}$ In this context, a large number of studies have focused on the carcinogenic role of FTO genes and their genetic variants in the development of various malignancies. ${ }^{11,33-39}$ A meta-analysis revealed that the 

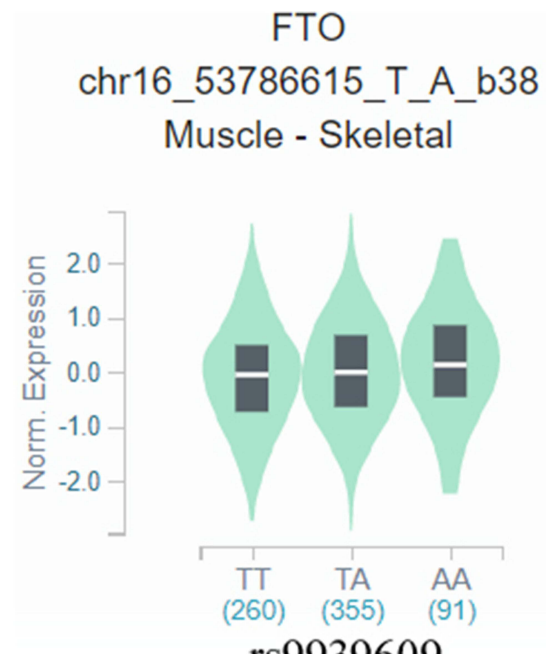

rs9939609
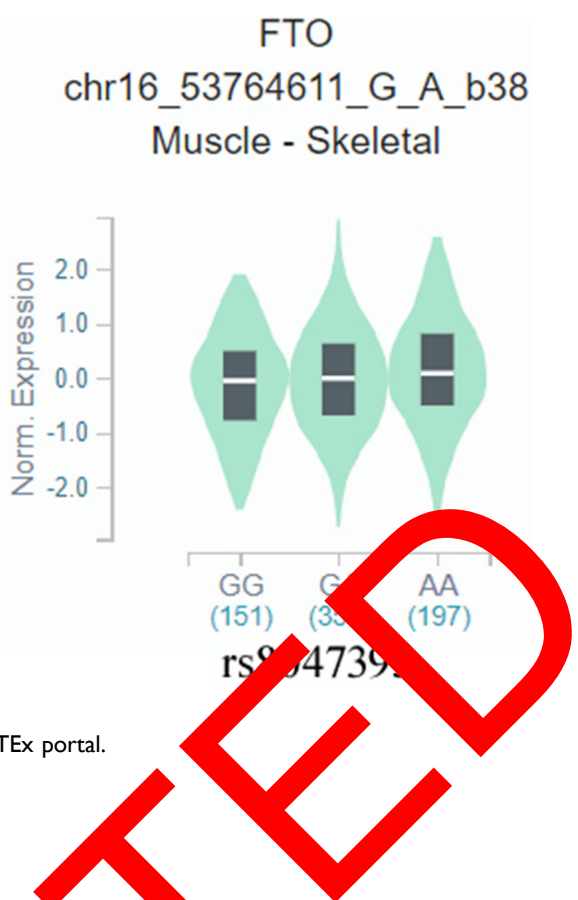

significant association between FTO rs9939609 polymorphism and cancer risk was found in the homozygote model and recessive model, especially for endometrial cancer and pancreatic cancer. ${ }^{25}$ No significant association between FTO rs8050136 polymorphism and canc risk has also been found. ${ }^{40}$ However, no studies have exa inea the role of FTO in the development of NPC to date. one study developed a m(6)A RNA me glat regu tors-based signature (including FTQ for pre cting th prognosis of head and neck squar us o cinoma.

In the current study, we re aled that b rs9939609 and rs8047395 were signif antly sociated hish risk of NPC. Meanwhile, G $\mathrm{X}$ showed isk allele $\mathrm{A}$ of rs9939609 and rs8 $/ 395$ were signitinantly associated with higher FTO RNA vels in skeletal muscle tissue. Considering card genic ect of FTO, the above results ce obora each and are logical. Our result for rs 17395 ralidated by a recent study about glioma, $\mathrm{w}$ also revealed allele $\mathrm{A}$ was a risk allele. ${ }^{42}$ However, the were also two other studies about central nervous system tumors and Wilms tumors which reported null or opposite results. ${ }^{13,30}$ We also found that rs 1477196 and rs9939609 were significantly associated with CR of NPC. Previous reports showed that expression alterations of multiple m6A enzymes, including FTO, could mediate the development of resistance of cancer cells to radiotherapy. ${ }^{43} \mathrm{Z}$. et al ${ }^{44}$ also reported that FTO could sulate the chemo adiotherapy resistance of cervical quamous o carcinoma by targeting $\beta$-catenin through RNA deme ylation. Further mechanistic studies on how F1 orphisms influence the radiotherapy efficiency \&NC are needed.

Our study has several limitations. First, the relatively moderate sample size might preclude us from observing some weak associations, although the collection of cases has cost us a lot of effort. Second, lack of geneenvironment interaction analyses due to sample size might affect the identification of clear phenotypic effects. Third, we only evaluated the radiotherapy effect of NPC and lacked long-term prognostic follow-up, which will be the focus of our next work. However, our research still reveals the important role of FTO in NPC, which will be helpful for more important research in the future.

In conclusion, our study identified that FTO polymorphisms contributed to the susceptibility and radiotherapy efficacy of NPC. These results shed light on the potential of establishing markers for predicting risk and treatment outcomes of NPC. Further functional studies of the FTO SNPs in NPC susceptibility and prognosis are warranted, which may lead to unearthing the genetic and pathophysiological mechanisms underlying this disease. 
Table 3 Association between Genetic Variations of the FTO Gene and the Efficacy of Radiotherapy in NPC Patients

\begin{tabular}{|c|c|c|c|c|}
\hline Variants & $\begin{array}{l}\text { Complete Remission } \\
\qquad(\mathrm{N}=\mathbf{2 5 4})\end{array}$ & $\begin{array}{c}\text { Non-Complete } \\
\text { Remission } \\
(\mathbf{N}=\text { I 13) }\end{array}$ & OR $(95 \% \mathrm{CI}) *$ & $P$-value \\
\hline \multicolumn{5}{|l|}{ rs 1477196} \\
\hline GG & 145 & 78 & I.00 (Reference) & \\
\hline AG & 95 & 32 & $1.66(1.01-2.74)$ & 0.047 \\
\hline AA & 14 & 3 & $2.61(0.76-8.94)$ & 0.127 \\
\hline A vs $G$ & & & $1.64(1.09-2.49)$ & 0.019 \\
\hline Dominant & & & $1.74(1.08-2.82)$ & 0.023 \\
\hline Recessive & & & $2.22(0.64-7.7 \mathrm{I})$ & 0.207 \\
\hline \multicolumn{5}{|l|}{ rs9939609 } \\
\hline TT & 187 & 70 & I.00 (Reference) & \\
\hline AG & 63 & 36 & $0.62(0.4-0.95)$ & 0.02 \\
\hline $\mathrm{AA}$ & 4 & 7 & $0.31(0$ & $0.0^{\circ}$ \\
\hline A vs $T$ & & & $0.61(0$ & .006 \\
\hline Dominant & & & & 0.011 \\
\hline Recessive & & & & 0.087 \\
\hline \multicolumn{5}{|l|}{ rs7206790 } \\
\hline $\mathrm{CC}$ & 167 & 82 & nce) & \\
\hline CG & 78 & 29 & $1.37(0.0 \quad 37)$ & 0.254 \\
\hline GG & 9 & 2 & $2.30(0.5-10.49)$ & 0.283 \\
\hline G vs $C$ & & & $(0.89-2.25)$ & 0.139 \\
\hline Dominant & & & $(0.85-2.4 I)$ & 0.176 \\
\hline Recessive & & & $2(0.46-9.76)$ & 0.335 \\
\hline \multicolumn{5}{|l|}{ rs8047395 } \\
\hline $\mathrm{AA}$ & 111 & & I.00 (Reference) & \\
\hline AG & 113 & & $1.25(0.72-2.18)$ & 0.428 \\
\hline GG & 30 & & $0.86(0.51-1.44)$ & 0.565 \\
\hline G vs $A$ & & & $1.02(0.76-1.36)$ & 0.899 \\
\hline Dominant & & & $1.14(0.63-2.09)$ & 0.665 \\
\hline Recessive & & & $0.79(0.47-1.33)$ & 0.369 \\
\hline
\end{tabular}

Note: *Adjusted for age, gender, smoking s As, drin status, EBV-V -IgA status, TNM stage, and Chemotherapy.

\section{Disclosure}

The authors declare tha hey ave no gonflicts of interest.

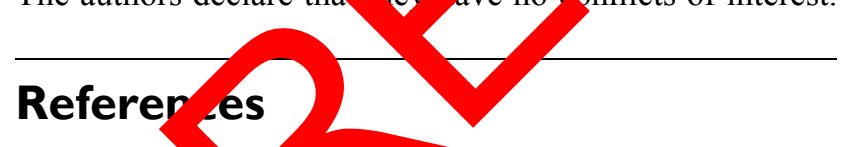

1. Chen YP, Q BC, Le Rlanchard P, Sun Y, Ma J. Nasopharyngeal inoma. Lancet. 2019;394:64-80.

2. Chang ET, Ye W, Za YX, Adami HO. The evolving epidemiology of Nasopharyngeal carci,ma. Cancer Epidemiol Biomarkers Prev. 2021;30:1035-1047.

3. Adham M, Kurniawan AN, Muhtadi AI, et al. Nasopharyngeal carcinoma in Indonesia: epidemiology, incidence, signs, and symptoms at presentation. Chin J Cancer. 2012;31:185-196.

4. Chen W, Zheng R, Baade PD, et al. Cancer statistics in China, 2015. CA Cancer J Clin. 2016;66:115-132.

5. Chang ET, Adami HO. The enigmatic epidemiology of nasopharyngeal carcinoma. Cancer Epidemiol Biomarkers Prev. 2006;15:1765-1777.

6. Ye ZM, Li LJ, Luo MB, et al. A systematic review and network meta-analysis of single nucleotide polymorphisms associated with pancreatic cancer risk. Aging. 2020;12:25256-25274.
7. Ma X, Zhang B, Zheng W. Genetic variants associated with colorectal cancer risk: comprehensive research synopsis, meta-analysis, and epidemiological evidence. Gut. 2014;63: 326-336.

8. van Veen EM, Brentnall AR, Byers $H$, et al. Use of single-nucleotide polymorphisms and mammographic density plus classic risk factors for breast cancer risk prediction. JAMA Oncol. 2018;4:476-482.

9. Shastry BS. SNPs: impact on gene function and phenotype. Methods Mol Biol. 2009;578:3-22.

10. Loos RJ, Yeo GS. The bigger picture of FTO: the first GWAS-identified obesity gene. Nat Rev Endocrinol. 2014;10:51-61.

11. Lan N, Lu Y, Zhang Y, et al. FTO - a common genetic basis for obesity and cancer. Front Genet. 2020;11:559138.

12. Garcia-Closas M, Couch FJ, Lindstrom S, et al. Genome-wide association studies identify four ER negative-specific breast cancer risk loci. Nat Genet. 2013;45:392-398,8e1-2.

13. Hua RX, Fu W, Lin A, et al. Role of FTO gene polymorphisms in Wilms tumor predisposition: a five-center case-control study. J Gene Med. 2021;23:e3348. 
14. Hoang T, Song D, Lee J, Lee EK, Hwangbo Y, Kim J. Association among BMI, genetic variants of FTO, and thyroid cancer risk: a hospital-based case-control study of the cancer screenee cohort in Korea. Cancer Res Treatment. 2020;53(3): 857-873.

15. Sigurdson AJ, Brenner AV, Roach JA, et al. Selected single-nucleotide polymorphisms in FOXE1, SERPINA5, FTO, EVPL, TICAM1 and SCARB1 are associated with papillary and follicular thyroid cancer risk: replication study in a German population. Carcinogenesis. 2016;37:677-684.

16. Hernandez-Caballero ME, Sierra-Ramirez JA. Single nucleotide polymorphisms of the FTO gene and cancer risk: an overview. Mol Biol Rep. 2015;42:699-704.

17. Lin Y, Ueda J, Yagyu K, et al. Association between variations in the fat mass and obesity-associated gene and pancreatic cancer risk: a case-control study in Japan. BMC Cancer. 2013;13:337.

18. Machiela MJ, Lindstrom S, Allen NE, et al. Association of type 2 diabetes susceptibility variants with advanced prostate cancer risk in the Breast and Prostate Cancer Cohort Consortium. Am J Epidemiol. 2012;176:1121-1129.

19. Lim U, Wilkens LR, Monroe KR, et al. Susceptibility variants for obesity and colorectal cancer risk: the multiethnic cohort and PAGE studies. Int J Cancer. 2012;131:E1038-43.

20. Ramos Chaves M, Boleo-Tome C, Monteiro-Grillo I, Camilo M, Ravasco P. The diversity of nutritional status in cancer: new insights. Oncologist. 2010;15:523-530.

21. Wang K, Yu XH, Tang YJ, Tang YL, Liang XH. Obesity: an emerging driver of head and neck cancer. Life Sci. 2019;233:116687.

22. Jung SY, Park DC, Kim SH, Yeo SG. Role of obesity in otorhinolaryngologic diseases. Curr Allergy Asthma Rep. 2019;19:34.

23. Relier S, Ripoll J, Guillorit H, et al. FTO-mediated cytoplasmic $\mathrm{m}(6)$ Am demethylation adjusts stem-like properties in colorectal cancer cell. Nat Commun. 2021;12:1716.

24. Chen J, Du B. Novel positioning from obesity to cancer: FT (6)A RNA demethylase, regulates tumour progression. J Can Clin Oncol. 2019;145:19-29.

25. Huang X, Zhao J, Yang M, Li M, Zheng J. Associ gene polymorphism (rs9939609 T/A) meta-analysis. Eur J Cancer Care. 2017;26

26. Lurie G, Gaudet MM, Spurdle AB, polymorphisms FTO rs9939609 and $4 \mathrm{R}$, 713 and enrometrial cancer risk in non-Hispanic ate women. oS One. 2011;6: e16756.

27. Mojaver M, Mokarian F, Ka Mrimi M, lehi M. Spevific TaqMan allelic discrimination ass for rs1477 and rs9939609 single nucleotide polymorphi of FTO gene de strated that there is no association bety these YPs and risk of breast cancer in Iranian women. Ao Biomed as. 2015;4:136.

28. Cho HW, Jin HS, Eo. The inter on between FTO rs9939609 and physic ity is a ciated a 2 -fold reduction in the risk of obes in Kor popula in J Human Biol. 2021;33:e23489.

29. Xu Y Ang J, Ya M, et al. Rs, 206790 and rs11644943 in FTO gene are as iated sesity in Chinese school-age population. PLoS Om 14;9:e108050.

4;9:e108050
30. Liao Y, Yuan L, Zhang Z, et al. No association between FTO gene polymorphisms and central nervous system tumor susceptibility in Chinese children. Pharmgenomics Pers Med. 2021;14:109-115.

31. Renehan AG, Zwahlen M, Egger M. Adiposity and cancer risk: new mechanistic insights from epidemiology. Nat Rev Cancer. 2015; 15:484-498.

32. Jia G, Fu Y, Zhao X, et al. N6-methyladenosine in nuclear RNA is a major substrate of the obesity-associated FTO. Nat Chem Biol. 2011;7:885-887.

33. Zhu K, Li Y, Xu Y. The FTO m(6)A demethylase inhibits the invasion and migration of prostate cancer cells by regulating total $\mathrm{m}(6) \mathrm{A}$ levels. Life Sci. 2021;271:119180.

34. Wang Y, Cheng Z, Xu J, et al. Fat mass and obesity-associated protein (FTO) mediates signal transducer and activator of transcription 3 (STAT3)-drived resistance of ancer to doxorubicin. Bioengineered. 2021;12:1874-18

35. Tao L, Mu X, Chen H, et al. FT nodifies the m level of MALAT and promotes bladder cancer pros sion. Clin $\operatorname{Tr}$ l Med. 2021;11: e310.

36. Zhao L, Kong X, Zh W, Wang Y, $\mathrm{F}^{\top}$ accelerates ovarian cancer cell growtb promot prolifera n, inhibiting apoptosis, and activating rop. vel Res Pract. 2020;216:153042.

37. Huang $\mathrm{H}$, ang $\mathrm{Y}$, andpal $\mathrm{N}$ et al. FTO-dependent $\mathrm{N}$ (6)-meth nosine modh tion Mhibit ovarian cancer stem cell self-re wal $\mathrm{x}$ blocking AMP signaling. Cancer Res. 2020;80:3200-3

38 arizadeh M, arvizi Omran S, Kordestani Z, Manshadi Dehghan H, Farida ar A, Houshmand M. Association of obesity-reland genetic variants (FTO and MC4R) with breast cancer risk: a popu ion-based case-control study in Iran. Iran J Biotechnol. 2019; $17: \mathrm{e} 2$

39. $\mathrm{R}$, Stanford S, Chen J. Critical enzymatic functions of FTO In obesity and cancer. Front Endocrinol. 2018;9:396.

7hao J, Huang X, Yang M, Li M, Zheng J. Association between the PYOrs 8050136 polymorphism and cancer risk: a meta-analysis. Fam Cancer. 2016;15:145-153.

41. Zhao X, Cui L. Development and validation of a m(6)A RNA methylation regulators-based signature for predicting the prognosis of head and neck squamous cell carcinoma. Am J Cancer Res. 2019;9:2156-2169.

42. He J, Yuan L, Lin H, et al. Genetic variants in m(6)A modification core genes are associated with glioma risk in Chinese children. Mol Ther Oncol. 2021;20:199-208.

43. Xiang M, Liu W, Tian W, You A, Deng D. RNA N-6-methyladenosine enzymes and resistance of cancer cells to chemotherapy and radiotherapy. Epigenomics. 2020;12:801-809.

44. Zhou S, Bai ZL, Xia D, et al. FTO regulates the chemo-radiotherapy resistance of cervical squamous cell carcinoma (CSCC) by targeting beta-catenin through mRNA demethylation. Mol Carcinog. 2018;57:590-597.

\section{Publish your work in this journal}

Pharmacogenomics and Personalized Medicine is an international, peer-reviewed, open access journal characterizing the influence of genotype on pharmacology leading to the development of personalized treatment programs and individualized drug selection for improved safety, efficacy and sustainability. This journal is indexed on the American Chemical Society's Chemical Abstracts Service (CAS). The manuscript management system is completely online and includes a very quick and fair peer-review system, which is all easy to use. Visit http://www.dovepress.com/testimonials.php to read real quotes from published authors. 